\title{
Extra corporeal shock wave lithotripsy in renal and ureteric stones: an institutional experience
}

\author{
Choudhury S. ${ }^{1}$, Pramanik S. ${ }^{2}$, Jana D. ${ }^{3}$, Kumar Pal D. ${ }^{*}$ \\ DOI: https://doi.org/10.17511/ijmrr.2019.i02.09 \\ ${ }^{1}$ Sunirmal Choudhury, Associate Professor, Department of Urology, Institute of Post Graduate Medical Education and Research, Kolkata, \\ West Bengal, India. \\ 2 Sandip Pramanik, Post Doctoral Trainee, Department of Urology, Institute of Post Graduate Medical Education and Research, Kolkata, West \\ Bengal, India. \\ 3 Debarshi Jana, Young Scientist (DST), Department of Gynaecology \& Obstetrics, Institute of Post Graduate Medical Education and \\ Research, Kolkata, West Bengal, India. \\ 4* Dilip Kumar Pal, Professor \& Head, Department of Urology, Institute of Post Graduate Medical Education and Research, Kolkata, West \\ Bengal, India.
}

Introduction: Urolithiasis is one of the most common clinical conditions in the history of medicine. Treatment methods include conservative, surgical treatment and extracorporeal shock wave lithotripsy (ESWL). Several stone characteristics are known to affect outcome of ESWL such as fragility, Hounsfield unit, size, site, composition etc. No study has been done till now regarding the efficacy and safety of ESWL in eastern Indian patients. Objectives: To assess the efficacy and safety of ESWL in the management of patients with renal and ureteral stones. Methods: 112 outpatients were treated with ESWL. Stone size, location, total number of shockwaves, stone-free rate, complications and adjunctive interventions were investigated. Chi-Square and Logistic Regression analyses were used, with $p<0.05$ set as the level of significance. Result \& Conclusion: The authors found significant association between the size and number of stones with fragmentation status. The authors found that stones of more than $11 \mathrm{~mm}$ size are more resistant to ESWL. Authors found statistically significant association between the number of ESWL sessions with fragmentation status. However, more than 3 sessions also did not help much. It was also found that complications were more in partially fragmented group and more adjunctive procedures were required in partially fragmented group. The authors also noticed that the stented or non stented status and total number of shocks were not significantly associated with the fragmentation status of stones.

Keywords: Extracorporeal Shock Wave Lithotripsy, Renal Stone, Upper Ureteric Stone

Corresponding Author

Dilip Kumar Pal, Professor \& Head, Department of Urology, Institute of Post Graduate Medical Education and Research, Kolkata, West Bengal, India. Email: drdkpal@yahoo.co.in
How to Cite this Article

Choudhury S, Pramanik S, Jana D, Pal DK. Extra corporeal shock wave lithotripsy in renal and ureteric stones: an institutional experience. Int J Med Res Rev. 2019;7(2):104-111.

Available From

https://ijmrr.medresearch.in/index.php/ijmrr/article/ view/1044
To Browse

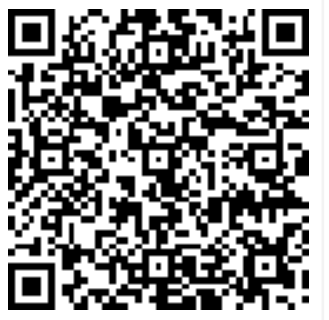

Manuscript Received 2019-04-04

Conflict of Interest No
Review Round 1 2019-04-14

Funding

Nil

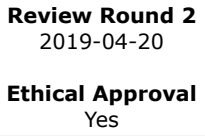

Ethical Approval Yes

Review Round 3

Accepted 2019-04-23

(c) 2019 by Sunirmal Choudhury, Sandip Pramanik, Debarshi Jana, Dilip Kumar Pal and Published by Siddharth Health Research and Social Welfare Society. This is an Open Access article licensed under a Creative Commons Attribution 4.0 International icense https://creativecommons.org/licenses/by/4.0/ unported [CC BY 4.0] 


\section{Introduction}

Urolithiasis is one of the most common clinical conditions in the history of medicine [1]. Another important aspect of this disease is its recurrence rate which spans from 60 to $80 \%$ over a span of 20 years [1]. The disease has got more prevalence in men; and there is possibility of $5 \%$ of women and $12 \%$ of men experiencing one episode of renal colic as a minimum during their lifetime. People in their 4th and 5th decade of life are usually affected with this disease. Hence it leads to a considerable economic loss to the family and society [1].

Calculi can be found in different zones of the urinary tract. $97 \%$ of calculi in developed countries dwell in Kidney and Ureter [2, 3]. Stone expulsion depends upon the size and location of the stones $[2,3]$. Ureteric stones on an average have $80 \%$ expulsion rates $[2,3]$. Therapeutic interventions are taken into consideration once a stone fails to be eliminated by conservative means.

Indications of therapeutic interventions for ureteric stones are: Stone size more than $7 \mathrm{~mm}$, low (less than $20 \%$ ) probability of spontaneous expulsion, absence of spontaneous elimination of stone of any size for an interlude of more than 30 days from the day of first episode of renal colic, sepsis, urinary tract infection, calculus anuria, as well as the patients' wish $[2,3]$.

Treatment methods include surgical treatment and extracorporeal shock wave lithotripsy (ESWL). Urete-rorenoscopy (URS), Percutaneous Nephrolithotomy (PCNL), Retrograde Intrarenal Surgery (RIRS) together with ESWL have almost entirely replaced open surgical procedures for stones in urinary tract in last 30 years [4]. But at times, the cost of treatment can have an impact on the choice of the primary approach to solve urolithiasis. Grasso et al in their study evaluated the costs of different endoscopic procedures and ESWL for ureteric calculi [4].

They concluded that the expenditure of ESWL sessions and endoscopic procedures were almost similar; but the expenditure of ESWL, were much higher because of more common supplementary interventions (31\% versus 3\%) [4]. Extracorporeal shock wave lithotripsy (ESWL) was introduced in the 1980s. Now it has become one of the standard suitable, non-invasive day care procedure meant for management of upper ureteric and renal calculi [5].
Amongst the different type of Shockwave generators, the original electrohydraulic Dornier HM-3 machine was first introduced. Since then, different machines have been introduced with new sources for generation of shock waves, for example piezoelectric and electro-magnetic sources. With time, attempt has been taken to reduce the size of lithotripters, and the present generation machines occupy less space. Focusing and imaging devices of ESWL machines have improved over the years for delivery of shock waves on the calculus in precise fashion [6]. Newer generation machines do not necessitate the use of anesthesia, resulting in more patient comfort and tolerance. However, they deliver less power and need multiple sessions [6].

The measurement of outcome of ESWL is done by stone fragmentation and clearance rate. Once the sessions of ESWL fail, it causes unnecessary damages to renal parenchyma by shock waves which lead to complications and these patients may need adjunctive procedures for stone clearance adding burden to the cost of treatment [7]. Several stone characteristics are known to affect outcome of ESWL such as fragility, Hounsfield unit, size, site, composition etc [8]. No study has been done till now regarding the efficacy and safety of ESWL in eastern Indian patients.

Hence the authors felt the need for one institution based study on this subject and they proceeded for it as the institute where the study has been done caters a large number of patients from different corners of eastern India.

\section{Materials and Methods}

This retrospective study was done at the Urology Department of one tertiary care institute in eastern India. Aim of Study was to assess the safety and efficacy of ESWL in the management of renal and upper ureteric stone. A number of 112 Patients who had undergone ESWL from December 2017 to November 2018 for the treatment of Renal or Upper Ureteric Stones were taken for the study. All patients with renal or ureteric stones were recorded retrospectively between December 2017 to November 2018. Complete data was collected from the ESWL Register which contains all clinical information pertaining to Pre ESWL status and Post ESWL status of the patients written sequentially and session wise. All patients had complete blood count $(\mathrm{CBC})$, urea and creatinine, coagulation profile, urinalysis, urine culture, before ESWL. 
Pre-treatment investigations were Plain $X$ Ray KUB (Kidney, Ureter and Bladder), IVU (Intravenous Urogram), ultrasonography or non-contrastunenhanced Computed Tomography (CT) scan. $X$ Ray and USG KUB done four weeks after each session were meant for evaluation of fragmentation and clearance. Stone size was determined by the widest diameter for renal and ureteric stones. Bowel preparation with Bisacodyl (Dulcolax) $10 \mathrm{mg}$ single oral dose on the night before ESWL, fasting from midnight before ESWL, one single dose of Fluoroquinolone (Levofloxacin $500 \mathrm{mg}$ ) on the night before the procedure were prerequisites according to protocol of the institution. ESWL was done under Fluoroscopic Guidance or USG Guidance or using both which the user felt necessary for. Energy level used for ESWL started from level A and gradually increased to level 4 depending upon stone fragmentation and patients' tolerability.

All patients had undergone ESWL on day care basis for a maximum of four sessions. No fragmentation or residual fragments of $>4 \mathrm{~mm}$ were considered as a failure and patients were offered alternative treatment. All ESWL sessions were carried out using oral analgesia in the form of Paracetamol (500 mg) and Diclofenac (50 mg) single doses. Patients were monitored clinically throughout the treatment sessions. At the end of treatment, patients were discharged on oral medications including Diclofenac (50 mg), Tamsulosin (0.4 mg) and Levofloxacin (500 mg).

All these were done according to the institution protocol. After reassessment of stones done after 4 weeks of first session, patients were subjected to another session of ESWL in case of no or inadequate fragmentation of the stone. Follow up data was also collected from the register which contains a follow up data upto four months after the first session. Assessment was done on the stone-free rate, number of shock waves, sessions, re-treatment rate, auxiliary procedure rate and complication rate. Complete clearance of ureteric stones and stonefree status or clinically insignificant residualfragments of $<4 \mathrm{~mm}$ in case of renal stones were defined as a treatment success. Stone fragmentation rate was correlated with the site and size of the stone. Age, sex, site of stone, size of stone, number of shock waves, number of sessions, status of pelvicalyceal system, status of stented or non-stented and requirement for auxiliary procedures before or after ESWL were also recorded.
Exclusion Criteria were uncorrected coagulation and bleeding disorders, pregnancy, gross obesity ( $>120$ $\mathrm{kg}$; due to technical difficulty in placing the patient in focus), patients taking anticoagulants, obstructed urinary tract distal to the stones, patients having incomplete information in the register (whose treatment is still incomplete).

For statistical analysis, data were entered into a Microsoft excel spreadsheet and then analysed by SPSS 24.0. and Graph Pad Prism version 5. Data had been summarized as mean and standard deviation for numerical variables and count and percentages for categorical variables. Student $T$ test and Chi Square test were done for statistical analysis. Unpaired proportions were compared by Chi-square test or Fischer's exact test, as appropriate-value $\leq 0.05$ was considered for statistically significant.

\section{Results}

Analysis was done in two groups; one group consisted of the patients who had complete fragmentation of stones and the other group had partially fragmented status. It was found that, $40(48.2 \%)$ patients had renal middle calyceal (MC) stones, $4(4.8 \%)$ patients had renal pelvis calculi, $30(36.1 \%)$ patients had renal upper calyceal (UC) and $9(10.8 \%)$ patients had upper ureteric stones in the group which had stones completely fragmented after ESWL.

In partially fragmented group, $13(44.8 \%)$ patients had renal MC stones, $1(3.4 \%)$ patient had renal pelvis stone, $10(34.5 \%)$ patients had renal UC stone and $5(17.2 \%)$ patients had upper ureteric stones. Association of site of stones with fragmentation status was not statistically significant $(p=0.8345)$. It was found that, in fragmented group, 79(95.2\%) patients had 1 stone and $4(4.8 \%)$ patients had 2 stones.

In partially fragmented group, 24(82.8\%) patients had 1 stone and 5(17.2\%) patients had 2 stones. Association of number of stones with fragmentation status was statistically significant $(p=0.0341)$. We found that in fragmented group, 36(43.4\%) patients were female and $47(56.6 \%)$ patients were male. In partially fragmented group, $9(31.0 \%)$ patients were female and $20(69.0 \%)$ patients were male. Association of sex with fragmentation status was not statistically significant $(p=0.2433)$. 
Table-1: Association of Stone Fragmentation with Sex of Patients, Stone Site, Number and Comorbidities of Patients.

\begin{tabular}{|c|c|c|c|c|c|c|}
\hline & ariables & Fragmented Number (\%) & Partially Fragmented Number (\%) & Total Number (\%) & Chi-Square Value & P-Value \\
\hline \multirow{4}{*}{ Site of Stones } & Renal Middle Calyx & $40(75.5)$ & $13(24.5)$ & $53(100.0)$ & \multirow[t]{4}{*}{.8623} & \multirow[t]{4}{*}{0.8345} \\
\hline & Renal Pelvis & $4(80.0)$ & $1(20.0)$ & $5(100.0)$ & & \\
\hline & Renal Upper Calyx & $30(75.0)$ & $10(25.0)$ & $40(100.0)$ & & \\
\hline & Upper Ureteric & $9(64.3)$ & $5(35.7)$ & $14(100.0)$ & & \\
\hline \multirow[t]{2}{*}{ Number of Stones } & Single & $79(76.7)$ & $24(23.3)$ & $103(100.0)$ & \multirow[t]{2}{*}{4.4875} & \multirow[t]{2}{*}{0.0341} \\
\hline & Multiple & $4(44.4)$ & $5(55.6)$ & $9(100.0)$ & & \\
\hline \multirow[t]{2}{*}{ Sex } & Female & $36(80.0)$ & $9(20.0)$ & $45(100.0)$ & \multirow[t]{2}{*}{1.3613} & \multirow[t]{2}{*}{0.2433} \\
\hline & Male & $47(70.1)$ & $20(29.9)$ & $67(100.0)$ & & \\
\hline \multirow[t]{3}{*}{ Comorbidities } & Diabetes Mellitus (DM) & $7(63.6)$ & $4(36.4)$ & $11(100.0)$ & \multirow[t]{3}{*}{3.5704} & \multirow[t]{3}{*}{0.1678} \\
\hline & Hypertension (HTN) & $10(58.8)$ & $7(41.2$ & $17(100.0)$ & & \\
\hline & No & $66(78.6)$ & $18(21.4)$ & $84(100.0)$ & & \\
\hline
\end{tabular}

It was found that in fragmented group, $7(8.4 \%)$ patients had Diabetes Mellitus (DM), 10(12.0\%) patients had Hypertension (HTN) and 66(79.5\%) patients had no comorbidities. In partially fragmented group, $4(13.8 \%)$ patients had DM, $7(24.1 \%)$ patients had HTN and $18(62.1 \%)$ patients had no comorbidities. Association of comorbidities with fragmentation status was not statistically significant $(p=0.1678)$. We found that in fragmented group, $73(100.0 \%)$ patients had stone density in Hounsfield unit (HFU) unknown. In partially fragmented group, 26(100.0\%) patients had HFU unknown. (Vide Table 1)

We found that in fragmented group, 16(19.3\%) patients had 2 numbers of sessions, 40(48.2\%) patients had 3 numbers of sessions and 27(32.5\%) patients had 4 numbers of sessions. In partially fragmented group, $7(24.1 \%)$ patients had 2 numbers of sessions, $5(17.2 \%)$ patients had 3 sessions and $17(58.6 \%)$ patients had 4 sessions of ESWL. Association of number of sessions with fragmentation status was statistically significant $(p=0.0106)$. It was found that in fragmented group, $10(12.0 \%)$ patients had previous history of ESWL,
$70(84.3 \%)$ patients had no previous history of ESWL or surgery and $3(3.6 \%)$ patients had previous history of URSL. In partially fragmented group, $1(3.4 \%)$ patient had previous history of ESWL, $25(86.2 \%)$ patients had no previous history of ESWL or surgery, $1(3.4 \%)$ patient had previous history of PCNL and $2(6.9 \%)$ patients had previous history of URSL. Association of history of previous ESWL or surgery with fragmentation status was not statistically significant $(p=0.1712)$. We found that in fragmented group, 21(25.3\%) patients had history of previous stone disease. In partially fragmented group, $8(27.6 \%)$ patients had history of previous stone disease.

Association of history of previous stone disease with fragmentation status was not statistically significant $(p=0.8089)$. It was found that in fragmented group, $73(88.0 \%)$ patients were non stented and $10(12.0 \%)$ patients had DJ stent in situ. In partially fragmented group, $22(75.9 \%)$ patients were non stented and $7(24.1 \%)$ patients had stent. Association of stented or non stented statuswith fragmentation status was not statistically significant $(p=0.1182)$. (Vide Table 2)

Table 2: Association of Stone Fragmentation with Number of ESWL Sessions, H/O Previous Surgery or ESWL or Stone Disease and DJ Stent in situ status.

\begin{tabular}{|c|c|c|c|c|c|c|}
\hline & Variables & $\begin{array}{c}\text { Fragmented Number } \\
(\%)\end{array}$ & $\begin{array}{l}\text { Partially Fragmented } \\
\text { Number }(\%)\end{array}$ & $\begin{array}{c}\text { Total Number } \\
(\%) \\
\end{array}$ & $\begin{array}{l}\text { Chi-Square } \\
\text { Value }\end{array}$ & $\begin{array}{c}\text { P- } \\
\text { Value }\end{array}$ \\
\hline \multirow[t]{3}{*}{ Number of Sessions } & 2 & $16(69.6)$ & $7(30.4)$ & $23(100.0)$ & \multirow[t]{3}{*}{9.0953} & \multirow[t]{3}{*}{$0.010 €$} \\
\hline & 3 & $40(88.9)$ & $5(11.1)$ & $45(100.0)$ & & \\
\hline & 4 & $27(61.4)$ & $17(38.6)$ & $44(100.0)$ & & \\
\hline \multirow{3}{*}{$\begin{array}{l}\text { H/O Previous ESWL or } \\
\text { Surgery }\end{array}$} & ESWL & $10(90.9)$ & $1(9.1)$ & $11(100.0)$ & \multirow[t]{3}{*}{5.0078} & \multirow[t]{3}{*}{0.1712} \\
\hline & No & $70(73.7)$ & $25(26.3)$ & $95(100.0)$ & & \\
\hline & $\begin{array}{l}\text { Percutaneous Nephrolithotomy } \\
\text { (PCNL) }\end{array}$ & $0(0.0)$ & $1(100.0)$ & $1(100.0)$ & & \\
\hline
\end{tabular}




\begin{tabular}{|c|c|c|c|c|c|c|}
\hline & Ureterorenoscopic lithotripsy (URSL). & $3(60.0)$ & $2(40.0)$ & $5(100.0)$ & & \\
\hline \multirow[t]{2}{*}{ H/O Previous Stone Disease } & No & $62(74.7)$ & $21(25.3)$ & $83(100.0)$ & \multirow[t]{2}{*}{0.0585} & \multirow[t]{2}{*}{0.8089} \\
\hline & Yes & $21(72.4)$ & $8(27.6)$ & $29(100.0)$ & & \\
\hline \multirow[t]{2}{*}{ Stented or Non Stented } & Non Stented & $73(76.8)$ & $22(23.2)$ & $95(100.0)$ & \multirow[t]{2}{*}{2.4398} & \multirow[t]{2}{*}{0.1182} \\
\hline & Stented & $10(58.8)$ & $7(41.2)$ & $17(100.0)$ & & \\
\hline
\end{tabular}

We found that in fragmented group, 74(89.2\%) patients had Fluoroscopy and Ultrasound guided ESWL and $9(10.8 \%)$ patients had Fluoroscopy (C arm) guided ESWL. In partially fragmented group, 24(82.8\%) patients had Fluoroscopy and Ultrasound guided and $5(17.2 \%)$ patients had only $\mathrm{C}$ arm guided ESWL. Association of $\mathrm{C}$ arm guided or USG guided with fragmentation status was not statistically significant $(p=0.3698)$. It was found that in fragmented group, $9(10.8 \%)$ patients had associated Hydronephrosis (HDN). In partially fragmented group, 5(17.2\%) patients had associated HDN. Association of associated HDN with fragmentation status was not statistically significant $(p=0.3698)$. We found that in fragmented group, $83(100.0 \%)$ patients had no adjunctive procedures.
In partially fragmented group, 2(6.9\%) patients had conservative management, $16(55.2 \%)$ patients had undergone PCNL, 6(20.7\%) patients had undergone RIRS and 5(17.2\%) patients had URSL done after ESWL for management of partially fragmented stones. Association of adjunctive procedures with fragmentation statuswas statistically significant $(p<0.0001)$. It was found that in fragmented group, $3(3.6 \%)$ patients had dysuria, $3(3.6 \%)$ patients had hematuria, $2(2.4 \%)$ patients had loin pain and $75(90.4 \%)$ patients had no complications. In partially fragmented group, $1(3.4 \%)$ patient had dysuria, $7(24.1 \%)$ patients had loin pain, $16(55.2 \%)$ patients had no complications and $5(17.2 \%)$ patients had UTI. Association of complications with fragmentation statuswas statistically significant $(p<0.0001)$. (Vide Table 3 )

\section{Table 3: Association of Stone Fragmentation with Associated Hydronephrosis, Adjunctive} Procedures and Complications.

\begin{tabular}{|c|c|c|c|c|c|c|}
\hline \multicolumn{2}{|r|}{ Variables } & $\begin{array}{c}\text { Fragmented Number } \\
(\%)\end{array}$ & $\begin{array}{l}\text { Partially Fragmented } \\
\text { Number }(\%)\end{array}$ & $\begin{array}{c}\text { Total Number } \\
(\%)\end{array}$ & $\begin{array}{l}\text { Chi-Square } \\
\text { Value }\end{array}$ & P-Value \\
\hline \multirow{2}{*}{$\begin{array}{l}\text { C Arm Guided or USG } \\
\text { Guided }\end{array}$} & Both & $74(75.5)$ & $24(24.5)$ & $98(100.0)$ & \multirow[t]{2}{*}{0.8043} & \multirow[t]{2}{*}{0.3698} \\
\hline & C Arm Guided & $9(64.3)$ & $5(35.7)$ & $14(100.0)$ & & \\
\hline \multirow{2}{*}{$\begin{array}{l}\text { Associated } \\
\text { Hydronephrosis }\end{array}$} & No & $74(75.5)$ & $24(24.5)$ & $98(100.0)$ & \multirow[t]{2}{*}{0.8043} & \multirow[t]{2}{*}{0.3698} \\
\hline & Yes & $9(64.3)$ & $5(35.7)$ & $14(100.0)$ & & \\
\hline \multirow[t]{5}{*}{ Adjunctive Procedures } & Conservative & $0(0.0)$ & $2(100.0)$ & $2(100.0)$ & \multirow[t]{5}{*}{112.0000} & \multirow[t]{5}{*}{$<0.0001$} \\
\hline & No & $83(100.0)$ & $0(0.0)$ & $83(100.0)$ & & \\
\hline & $\begin{array}{l}\text { Percutaneous Nephrolithotomy } \\
\text { (PCNL) }\end{array}$ & $0(0.0)$ & $16(100.0)$ & $16(100.0)$ & & \\
\hline & $\begin{array}{l}\text { Retrograde Intrarenal Surgery } \\
\text { (RIRS) }\end{array}$ & $0(0.0)$ & $6(100.0)$ & $6(100.0)$ & & \\
\hline & $\begin{array}{l}\text { Ureterorenoscopic lithotripsy } \\
\text { (URSL) }\end{array}$ & $0(0.0)$ & $5(100.0)$ & $5(100.0)$ & & \\
\hline \multirow[t]{5}{*}{ Complications } & Dysuria & $3(75.0)$ & $1(25.0)$ & $4(100.0)$ & \multirow[t]{5}{*}{31.2620} & \multirow[t]{5}{*}{$<0.0001$} \\
\hline & Hematuria & $3(100.0)$ & $0(0.0)$ & $3(100.0)$ & & \\
\hline & Loin Pain & $2(22.2)$ & $7(77.8)$ & $9(100.0)$ & & \\
\hline & No & $75(82.4)$ & $16(17.6)$ & $91(100.0)$ & & \\
\hline & Urinary Tract Infection (UTI) & $0(0.0$ & $5(100.0)$ & $5(100.0)$ & & \\
\hline
\end{tabular}

We found that in fragmented group, the mean size of stones (Mean \pm S.D.) of patients was $9.7952 \pm$ $1.5362 \mathrm{~mm}$.In partially fragmented group, the mean size of stones (Mean \pm S.D.) of patients was $11.0690 \pm 2.1536 \mathrm{~mm}$.
Distribution of mean size of stones with fragmentation statuswas statistically significant $(p=0.0008)$. It was found that in fragmented group, the mean age (Mean \pm S.D.)of patients was $36.8072 \pm 8.8144$ years. 
In partially fragmented group, the mean age (Mean \pm S.D.) of patients was $37.9655 \pm 9.6824$ years. Distribution of mean age with fragmentation statuswas not statistically significant $(p=0.5539)$. We found that in fragmented group, the mean total number of shocks (Mean \pm S.D.) of patients was
$7481.9277 \pm 1699.9386$. In partially fragmented group, the mean total number of shocks (Mean \pm S.D.) of patients was 8158.6207 \pm 2185.5887 . Distribution of mean total number of shocks with fragmentation statuswas not statistically significant $(p=0.0903)$. (Vide Table 4)

Table-4: Association of Stone Fragmentation with Age of Patients, Stone Size, Number of Shocks of ESWL

\begin{tabular}{|l|l|l|l|l|l|l|l|l|}
\hline \multicolumn{2}{|c}{} & Number & \multicolumn{1}{|c|}{ Mean } & \multicolumn{1}{|c|}{ SD } & Minimum & \multicolumn{1}{c|}{ Maximum } & \multicolumn{1}{c|}{ Median } & p-value \\
\hline \multirow{3}{*}{ Size of stones $(\mathrm{mm})$} & Fragmented & 83 & 9.7952 & 1.5362 & 7.0000 & 15.0000 & 10.0000 \\
\cline { 2 - 9 } & Partially Fragmented & 29 & 11.0690 & 2.1536 & 7.0000 & 15.0000 & 10.0000 \\
\hline \multirow{2}{*}{ Age } & Fragmented & 83 & 36.8072 & 8.8144 & 20.0000 & 54.0000 & 36.0000 & 0.5539 \\
\cline { 2 - 9 } & Partially Fragmented & 29 & 37.9655 & 9.6824 & 20.0000 & 58.0000 & 38.0000 & \\
\hline \multirow{2}{*}{ Total number of shocks } & Fragmented & 83 & 7481.9277 & 1699.9386 & 4000.0000 & 10000.0000 & 7500.0000 & 0.0903 \\
\cline { 2 - 8 } & Partially Fragmented & 29 & 8158.6207 & 2185.5887 & 4000.0000 & 10000.0000 & 9500.0000 & \\
\hline
\end{tabular}

In a nutshell, the authors found significant association between the size and number of stones with fragmentation status. The authors found that stones of more than $11 \mathrm{~mm}$ size are more resistant to ESWL. Authors found statistically significant association between the number of ESWL sessions with fragmentation status. However, more than 3 sessions also did not help much.

It was also found that complications were more in partially fragmented group and more adjunctive procedures were required in partially fragmented group. The authors also noticed that the stented or non stented status and total number of shocks were not significantly associated with the fragmentation status of stones. No comment could me made about the association between stone density in Hounsfield unit and fragmentation status due to lack of adequate data.

\section{Discussion}

ESWL in the treatment of renal and upper ureteric stones has indeed reduced hospitalization time and morbidity, and is cost effective as well. But ESWL is also associated with obstructive and infective complications. ESWL therapy is done in our set up, under no anaesthesia and is administered in an outpatient setting. The newer generation of lithotripters usually use smaller focal zones and imparts higher peak-point pressures [9]. The authors in their study had a success rate of $75.5 \%$, $80 \%, 75 \%$ for renal middle calyceal stones, pelvic stones and upper calyceal stones respectively and $64.3 \%$ for ureteric stones.
These results happen to be comparable with documented success rates in literature (40-91\%) [10]. Auxiliary procedures were required in few cases in the present series which corroborates with what has been reported in literature [11]. Adjunctive procedures were more required in the patients who had partial fragmentation of stones in this study. The efficacy of the tamsulosin (oral 0.4 $\mathrm{mg} / \mathrm{d}$ for 1 month) as an adjunct to ESWL for expulsion of ureteral and renal stones wasfound to be effective and it caused significant improvement in the stone clearance rate. Moreover, it was also associated with a significantly lesser interval to the expulsion of stone fragments, significantly lower rehospitalization rate [12]. Stone types are usually categorized by density measurements on computerised tomography (CT) scan.

Literatures say that it is not logical to predict ESWL success with stone densities. These also cannot predict the number of ESWL sessions required for complete fragmentation [13]. Nevertheless, stone density can help to predict the outcome of ESWL. Stones with densities $<500$ Hounsfield units (HFU) are more likely to be fragmented than the stones with densities $\geq 800 \mathrm{HFU}$ which are less likely to be fragmented [14]. The authors were not able to comment on association of stone density with fragmentation status in this study due to lack of data regarding Hounsfield unit of stones.

Double-J (DJ) stent insertion for ESWL of renal calculi may be done as a part of therapy for obstructive pyelonephritis, high grade obstruction, refractory colic etc or as a prophylactic measure before ESWL of renal calculi. 
Currently, European Urological Association (EUA) guidelines and American urologist Association (AUA) guidelines recommend a DJ stenting before ESWL for renal pelvic stones of $2 \mathrm{~cm}$ and above [15]. Mohayuddin $\mathrm{N}$ et all in their study comparing the outcome of ESWL for a renal pelvic stone of $2 \mathrm{~cm} \pm$ $2 \mathrm{~mm}$ with and without DJ stent found that Pre ESWL DJ stenting for a $2 \mathrm{~cm} \pm 2 \mathrm{~mm}$ renal stone was not beneficial. However, the incidence of ureteric colic was significantly lower in the stented group. Lower urinary tract symptoms (LUTS) were also significantly higher in the stented group [16]. However the authors, in this study, were not able to find any significant association between the stented or non stented status and fragmentation of stone by ESWL.

Complication rate of ESWL in the present study is $18.75 \%$ (21/112) overall, with preponderance of minor complications. However Massive retroperitoneal hemorrhage after extracorporeal shock wave lithotripsy (ESWL) leading to patient death has also been reported in literature [17]. ESWL can also have some other serious complications, like gastrointestinal injury in $1.8 \%$ of cases, including colonic perforation or duodenal erosions [18]. Literature does not support any association between ESWL and the subsequent long-term risk of hypertension [19].

There were more complications in the partially fragmented group in this study.Mohammed S. AlMarhoon et all in their study found that the mean number of sessions required for clearance of renal stones was 1.3. The necessity for three sessions was non-significantly affected by stone size. [20]In this study, the authors found significant association between the size as well as number of stones with fragmentation status. It was also found that stones of more than $11 \mathrm{~mm}$ size were more resistant to ESWL. Authors found statistically significant association between the number of ESWL sessions with fragmentation status and no statistically significant association with number of shocks. However, on subgroup analysis (Table 2), it was found that more than 3 sessions did not help much.

\section{Conclusion}

The authors found statistically significant association between numbers of sessions and fragmentation status of stones whereas association of total number of shocks and presence or absence of DJ stent with fragmentation status was not statistically significant.
Association of adjunctive procedures with fragmentation status was statistically significant as the stones which were partially fragmented required more adjunctive procedures.The authors also noticed more complications in partially fragmented group and it was statistically significant. However more extensive and long term study is required to find out other modifiable factors responsible for stone fragmentation.

\section{Acknowledgements}

Not Applicable

\section{Specific author's contribution}

01. First Author: Research Idea, Data Collection, Literature Search, Statistical Analysis, Writing of Manuscript

02. Second Author: Literature Search, Statistical Analysis, Writing of Manuscript

03. Third Author: Statistical Analysis, Writing of Manuscript

04. Fourth Author (Corresponding Author): Research Idea, Literature Search, Correspondence to Editor for Publication

\section{Reference}

01. Prstojevic JK, Junuzovic D, Hasanbegovic M, et al. Characteristics of calculi in the urinary tract. Mater Sociomed. 2014 Oct;26(5)297-302.

doi: $\quad 10.5455 / \mathrm{msm} .2014 .26 .297-302 \quad$ [Crossref]

02. Marshall LS, Tanagho EA, McAninch JW. Urinary Stone Disease, In- Tanagho EA, editor, Smith's General Urology. 16th edition, San FranciskoLange Medical Book. 2004.

[Crossref]

03. Mennon M, Resnick M, Retik $A B$, et al. Urinary Lithiasis- Etiology,Diagnosis and Medical Management, In- Walsh PC, Retik AB, Vaughan ED, Wein AJ, et al, editors Campbell's Urology. 8ht ed, Philadelphia, PA- Saunders Elsevier. 2002;3287-3289.

[Crossref]

04. Grasso M, Beaghler M, Loisides P. The case for primary endoscopic management of upper urinary tract calculi- II, Cost and outcome assessment of 112 primary ureteral calculi. Urology. 1995;45;372-376.

[Crossref] 
05. Chaussy C, Brendel W, Schmiedt E. Extracorporeally induced destruction of kidney stones by shock waves. Lancet. 1980 Dec $13 ; 2(8207) 1265-8$.

[Crossref]

06. Hassouna ME, Oraby S, Sameh W, et al. Clinical experience with shock-wave lithotripsy using the Siemens Modularis Vario lithotripter. Arab J Urol. 2011 Jun;9(2)101-5.

doi: 10.1016/j.aju.2011.06.004 [Crossref]

07. Nomikos MS, Sowter SJ, Tolley DA. Outcomes using a fourth-generation lithotripter- a new benchmark for comparison?. BJU Int. 2007 Dec;100(6)1356-60.

[Crossref]

08. Bon D, Dore B, Irani J, et al. Radiographic prognostic criteria for extracorporeal shockwave lithotripsy- a study of 485 patients. Urology. 1996 Oct;48(4)556-60.

[Crossref]

09. Augustin H. Prediction of stone-free rate after ESWL. Eur Urol. 2007 Aug;52(2)318-20.

[Crossref]

10. Jamshaid A, Ather MH, Hussain G, Khawaja KB. Single center, single operator comparative study of the effectiveness of electrohydraulic and electromagnetic lithotripters in the management of 10 - to $20-\mathrm{mm}$ single upper urinary tract calculi. Urology. 2008;72;991-995.

[Crossref]

11. Lalak NJ, Moussa SA, Smith G, et al. The Dornier Compact Delta lithotripter- the first 150 ureteral calculi. J Endourol. 2002 Nov;16(9)6458.

DOI: $10.1089 / 089277902761402970$ [Crossref]

12. Georgiev MI, Ormanov DI, Vassilev VD, Dimitrov PD, Mladenov VD, Popov EP, et al. Efficacy of tamsulosin oral controlled absorption system after extracorporeal shock wave lithotripsy to treat urolithiasis. Urology. 2011;78;1023-1026. [Crossref]

13. Goren MR Buoctmiploh. Can we predict the success of shock wave lithotripsy by stone density measured with computerised tomography. Eur Urol Suppl. 2006;5;186.

[Crossref]
14. Sanjeev Pathaka. Radiological determination of stone density and skin-to-stone distance-Can it predict the success of extracorporeal shock wave lithotripsy?. $\mathrm{Br} \mathrm{J}$ Med Surg Urol. $2009 ; 2 ; 180-184$.

[Crossref]

15. European Association of urology. Home page of European Association of Urology. [Cited December 2011].

Available from: [Article] [Crossref]

16. Mohayuddin N, Malik HA, Hussain M, et al. The outcome of extracorporeal shockwave lithotripsy for renal pelvic stone with and without JJ stent-a comparative study. J Pak Med Assoc. 2009 Mar;59(3)143-6.

[Crossref]

17. Inoue $H$, Kamphausen $T$, Bajanowski $T$, et al. Massive retroperitoneal haemorrhage after extra-corporeal shock wave lithotripsy (ESWL). Int J Legal Med. 2011 Jan;125(1)75-9.

doi: 10.1007/s00414-010-0489-6 [Crossref]

18. Maker V, Layke J. Gastrointestinal injury secondary to extracorporeal shock wave lithotripsy- a review of the literature since its inception. J Am Coll Surg. 2004;198;128-135. [Crossref]

19. Krambeck $A E$, Rule $A D$, Li $X$, Bergstralh $E J$, Gettman MT, Lieske JC. Shock wave lithotripsy is not predictive of hypertension among community stone formers at long-term followup. J Urol. 2011;185;164-169.

[Crossref]

20. Al-Marhoon M, Shareef O, Al-Habsi I, Al Balushi A, Mathew $\mathrm{J}$ and Venkiteswaran $\mathrm{K}$. Extracorporeal Shock-wave Lithotripsy Success Rate and Complications- Initial Experience at Sultan Qaboos University Hospital. Oman Medical Journal. 2013;28;255-259.

[Crossref] 